\title{
A Conceptual and Procedural Research on the Hierarchical Structure of Mathematics Emerging in the Minds of University Students: An Example of Limit-Continuity-Integral-Derivative
}

\author{
Arif Dane ${ }^{1}$, Ömer Faruk Çetin ${ }^{1}$, Fatih Baş ${ }^{1,2} \&$ Meryem Özturan Sağırlı ${ }^{1}$ \\ ${ }^{1}$ Faculty of Education, Erzincan University, Erzincan, Turkey \\ Correspondence: Fatih Baş, Faculty of Education, Erzincan University, Erzincan, Turkey. Tel: \\ 90-446-224-0089-42218
}

Received: February 18, 2016

Accepted: February 29, 2016

Online Published: March 2, 2016

doi:10.5430/ijhe.v5n2p82

URL: http://dx.doi.org/10.5430/ijhe.v5n2p82

\begin{abstract}
In this present study, it was aimed to investigate whether the hierarchical structure of mathematics emerged in university students' minds or not, considering the concepts of limit, continuity derivative and integral from the perspective of students in the department of secondary school mathematics teacher training and the department of mathematics in the faculty of science and letters. The study, designed with the case study methodology, was carried out with 100 participants. Data were collected with the research group via a survey form including totally five questions; one of which is conceptual the other four are operational and analysed with the descriptive analysis. From the results of the research, it was found out that the participants could not learn the concepts of limit-continuity-derivative-integral conceptually and could not constitute the hierarchical structures among these concepts in their minds. Nevertheless, it was determined that the participants learned the procedural knowledge of each concept independent from the other. From these results, it can be recommended that placing activities emphasizing on the relationships among the concepts in teaching the concepts should be applied more.
\end{abstract}

Keywords: Hierarchical structures of mathematics, Conceptual learning, Procedural knowledge, Limit, Continuity, Derivative, Integral

\section{Introduction}

The knowledge in the process of mathematics teaching can be grouped under two headings as conceptual and procedural. Conceptual knowledge; consists of the hidden meanings under rules, generalizations, the relations among these and the procedures (Hiebert \& Lefevre, 1986; Rittle- Johnson \& Schneieder, 2012). Shortly, concept knowledge is the knowledge of meaning (Bekdemir \& Işık, 2007). Unless the students understand all the descriptions related to a subject in mathematics, it will not be easy to understand it entirely (Kandemir, 2004). Therefore, the subject should be learned within the scope of the descriptions, concepts and the ability to interpret the concepts (Özdemir, 2000). Procedural knowledge is the knowledge of symbols, arithmetical operations and routine rules, which are used to solve the problems (Hiebert \& Lefevre, 1986). As the relevant sorts of the knowledge are not depended, in order to provide the desired success in mathematics, it is crucial to learn these two sorts of knowledge adequately and well balanced. Therefore, it can require more conceptual knowledge in order to make a certain operation.

The mathematical concepts are abstract, complex and hierarchical (Nesbit, 1996). Moreover, in formal education, as the class level increases, the abstractness, complexity and hierarchical levels of mathematical concepts increase, too (Çetin, Dane and Bekdemir, 2012). For instance, the concepts of limit, continuity, derivative and integral placed in relevant departments of science; engineering and education faculties have extremely abstract and hierarchical forms. As the concept of limit, which is the base for other concepts, placed first in the sequence, in order to describe this concept, the concepts as neighbourhood, accumulation point etc. are used. However, from the results of the researches, it is claimed that the students have learning difficulties in the concepts of limit, continuity, derivative, integral (Baki and Çekmez, 2012; Biber and Argün, 2015; Cornu, 1991; Davis and Vinner, 1986; Hashemi, Abu, Kashefi, Mokhtar and Rahimi, 2015; Kula and Bukova Güzel, 2015; Özkaya, Işık and Konyalığlu, 2014; Sağlam and Bülbül, 2012; Szydlik, 2000; Tall and Vinner, 1981; Tangül, Barak and Özdaş, 2015; Williams, 1991) or misconceptions (Akbulut and Işı1k, 2005; Baştürk and Dönmez, 2011; Bergthold, 1999; Bezuidenhout, 2001; Cornu, 
1991; Davis and Vinner, 1986; Dönmez, 2009; Gray and Tall,1991; Jordaan, 2005; Orton, 1983; Szydlik, 2000; Tall and Vinner, 1981; Tall, 1993; Williams,1989, 1991). Çetin, et al. (2012) claimed that on the bases of most of these difficulties and misconceptions, that there are deficiencies related to the concept of accumulation point. Because, in order that the limit of a function exists at any point, firstly, it is necessary that point must be the accumulation point (Balc1, 1997). Therefore, the conceptual knowledge which should be obtained related to a set which contains accumulation point, is a circumstance that the limit, continuity, derivative and integral concepts in this set to be learned.

This situation makes us think of the question whether undergraduate students have knowledge of the hierarchical structure of mathematics or not. From this point, in this study, it was aimed to investigate whether the hierarchical structure of mathematics emerged in university students' minds or not, the concepts of limit, continuity, derivative and integral from the perspective of students in the department of secondary school mathematics teacher training and the department of mathematics in the faculty of science and letters.. With this aim, these following research questions were asked;

1. What are the conceptual learning levels of students in the department of secondary school mathematics teacher training and the department of mathematics in the faculty of science and letters related to limit, continuity, derivative and integral?

2. What are the procedural learning levels of students in the department of secondary school mathematics teacher training and the department of mathematics in the faculty of science and letters related to limit, continuity, derivative and integral?

\section{Method}

This study was designed with the case study method, which is one of the interactive designs of qualitative approaches and enables to examine the research topic deeply in order to reveal all the data in detail (McMillan, 2000, p. 316; Patton, 2002, p. 447). In the case study method, it is necessary to determine a case to start the research, handle the determined case more deeply, and carry it to complex fields (Bogdan and Biklen, 2007, p. 59). The conceptual and procedural learning levels related to the determined mathematical concepts determined within the scope of this study were handled in detail.

\subsection{Study Group}

The study group consists of a hundred (100) participants who are still fourth-grade-students at the department of secondary school mathematics teacher training at a faculty of education and the department of mathematics in the faculty of science and letters in a medium province located eastern Turkey. Constituting the study group was completed in two stages. At the first stage, the research university was determined using the convenience sampling that enables constituting the research group among the ones who can easily be reached and economical in terms of time - money-effort etc. (Patton, 2002, p.242). At the second stage, typical situation sampling method enabling some previously determined significance criteria, preferred for enabling all the situations to be studied and revised (Patton, 2002, p.238) was determined. Considering the criterion that all of the lessons containing these concepts need to be completed, it was decided to carry out the study with the students at the department of secondary school mathematics teacher training at a faculty of education and the department of mathematics in the faculty of science and letters in the determined university.

In the Department of Mathematics at the Faculty of Science and Letters, the concepts 'limit, continuity, derivative and definitive integral which consist of various forms of accumulation point' mainly place in first grade the lessons as Analysis-I and II; in second grade Analysis -III and IV, in third grade; Complex Functions Theories-I and II, Topology-I and II; in fourth grade Real and Functional Analysis, in the department of secondary school mathematics in Faculty of Education; in second grade Analysis-I and II and in third grade Analysis-III.

\subsection{Data Collection Tool}

Data, in this study, were collected via a survey form named as the Conceptional-Procedural Knowledge Form Related to the Concepts of Limit-Continuity-Derivative-Integral (CPKFRCLCDI). CPKFRCLCDI consists of totally five questions- related to the limit, continuity, derivative and definite integral-one is investigating the conceptual the other four are investigating procedural knowledge. It was prepared by four experts in the field and one language expert. The questions placed in CPKFRCLCDI are as follows;

1. What can be expressed about the solutions of the problems below related to the function given as $f: Z \rightarrow$ $Z$ ve $f(x)=2 x+1$ ? Explain shortly. 
2. Calculate the limit oflim $\operatorname{lit}_{x \rightarrow 1}(2 x+1)$.

3. Does the function $f(x)=2 x+1$ continual at the point of $\mathrm{x}=1$ ?

4. Calculate the derivative of $\frac{d}{d x}(2 x+1)$.

5. Calculate the definite integral of $\int_{1}^{3}(2 x+1) d x$.

With the help of the questions placed in the form, the concepts limit, continuity, derivative and integral and relevant solutions were specialized to accumulation point and more specifically to the concept of neighbourhood. That is, the function given in the problem was defined in the set of integers and including the point 1 , each neighbourhood of the determination set is not related to the set, the elements of the determination set are not the accumulation points. Therefore, as it is not possible to approach the point $\mathrm{x}=1$ from right or left, limit at this point cannot be determined. As the limit cannot be determined, the continuity, derivative and integral related to this concept cannot be determined, neither. Thus, as the students' set of integers do not obtain an accumulation point, their thoughts of limit, continuity, derivative and integral cannot be calculated, in a way, will give information about their understanding the hierarchical structure of mathematics.

\subsection{Data Collection and Analysis}

During a course period, the participants were asked to answer the questions stated in CPKFRCLCDI written and individually. The students were banned to affect each other during the process of answering. The forms filled by the participants were collected at the end of the determined period, they were archived with coding the faculty of science, and letters as ' $F$ ' and the faculty of education as ' $E$ ', and the numbers after the letters described the sequence numbers.

Four experts, who are experienced in analysis and quantitative research, studying spontaneously and together, made the analysis of the collected data. During the process of analysis in which the consensus was taken the base, the descriptive analysis method whose conceptual structure was previously determined (Yıldırım and Şimşek, 2005) was applied. Therefore, according the joint decision of the researchers, the data within the scope of the first question was analysed based on expressing-not expressing opinions about the relevant solution, the data within the scope of other questions, the ability of making- not making the operations about the relevant concept correctly. The gathered findings are indicated with the following Tables.

\section{Findings}

In this section, the gathered findings related to the sub-problems are presented in order.

3.1 The Findings Related to the First Sub-problem; What are the conceptual learning levels of students in the department of secondary school mathematics teacher training and the department of mathematics in the faculty of science and letters related to limit, continuity, derivative and integral?

Within the scope of this sub-problem, the solutions to the questions; for the function as ' $f: Z \rightarrow Z$ and $f(x)=2 x+$ 1' ' $\lim _{x \rightarrow 1}(2 x+1)$ ', 'is f function continual at the point $x=1$, ' $\frac{d}{d x}(2 x+1)$ ' and ' $\int_{1}^{3}(2 x+1) d x$ ' were analysed through expressing-not expressing opinions. The gathered findings are indicated in Figure 1. 


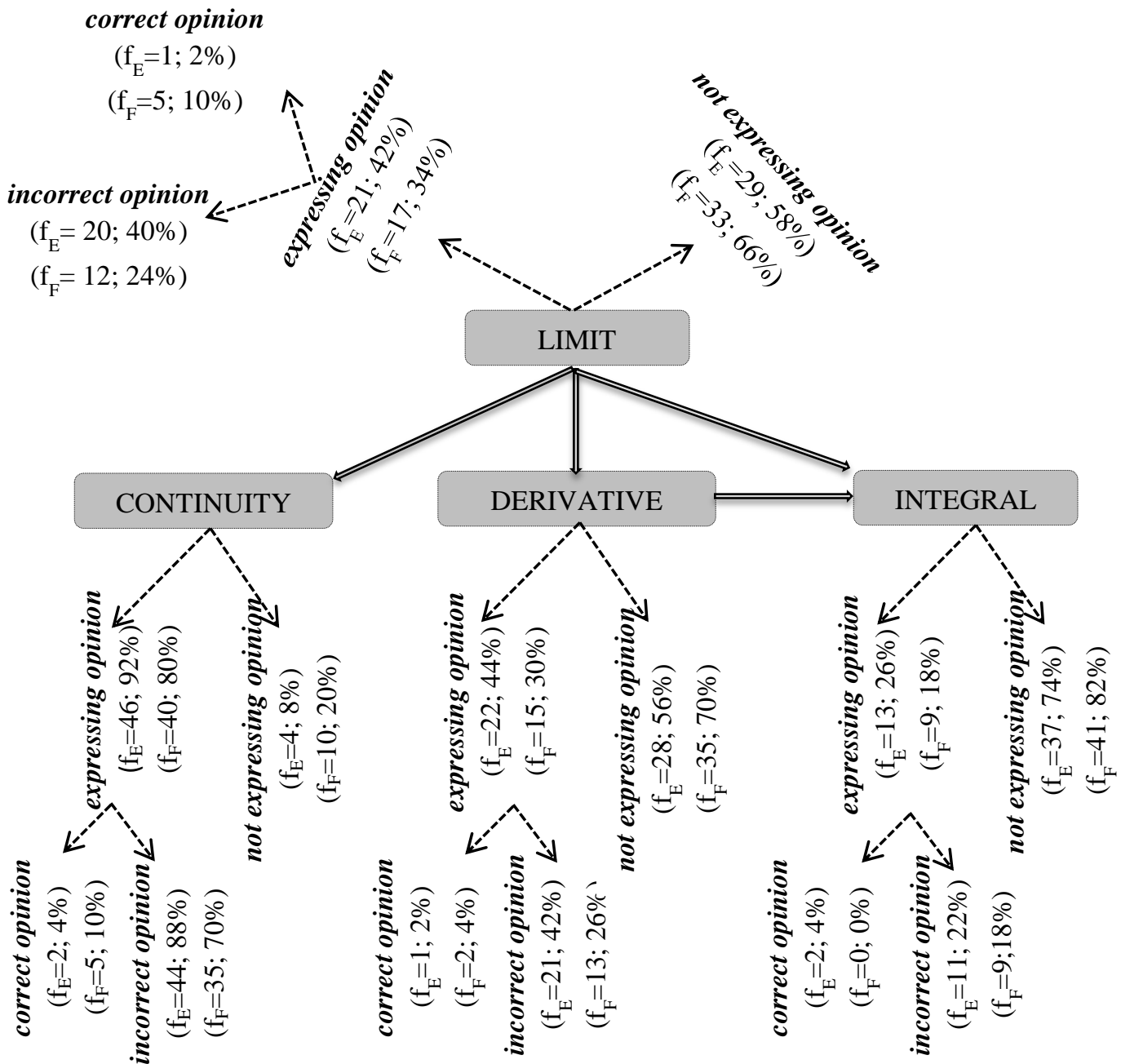

Figure 1. The distribution of solutions to the conceptual problem by the participants

As it is indicated in Figure 1, the percentage of those who expressed the correct opinion related to that there was no solution of the problem of limit stated in CPKFRCLCDI, according to the faculties are: for the Faculty of Education is $2 \%$ and for the Faculty of Science and Letters is $10 \%$. Totally, while $6 \%$ of all the participants expressed opinion as there was no solution for the problem related to the limit, $32 \%$ expressed incorrect answers about the solution and $62 \%$ of them directly started to solve without expressing opinion. The expressions of F3 (correct opinion) and E42 (incorrect opinion) coded participants related to the existence of the solution are as follows;

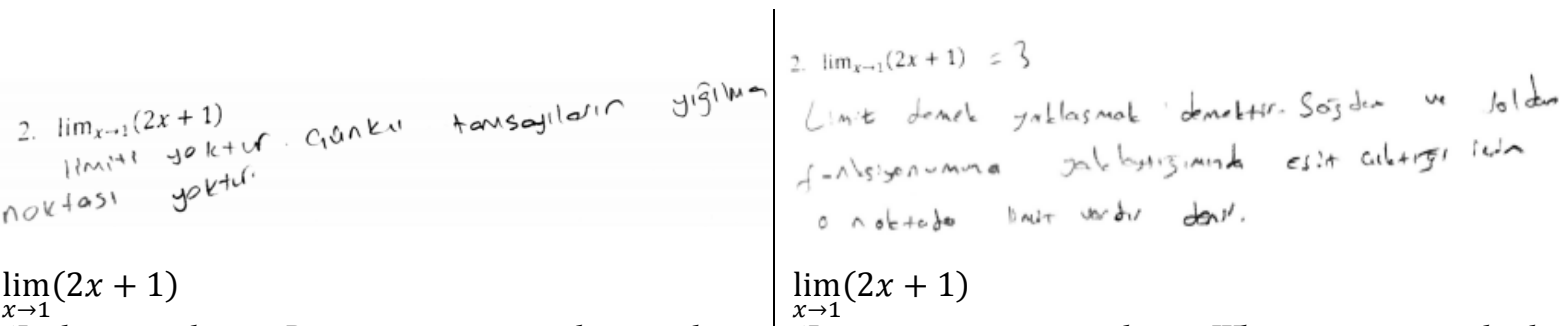

$$
\begin{aligned}
& \text { 'It has no limit. Because, integers do not have 'Limit means approaching. When we approach the }
\end{aligned}
$$

Figure 2. F3 coded student's expression

Figure 3. E42 coded student's expression 
As it is indicated in Table 1, the percentage of those who expressed the correct opinion related to that there was no solution of the problem of continuity stated in CPKFRCLCDI, according to the faculties are: for the Faculty of Education is $4 \%$ and for the Faculty of Science and Letters $10 \%$. Totally, while $7 \%$ of all the participants expressed opinion as there was no solution for the problem related to the continuity, $79 \%$ expressed incorrect answers about the solution and $14 \%$ of them directly started to solve without expressing opinion. The expressions of F33 (incorrect opinion) and E5 (correct opinion) coded participants related to the existence of the solution are as follows;

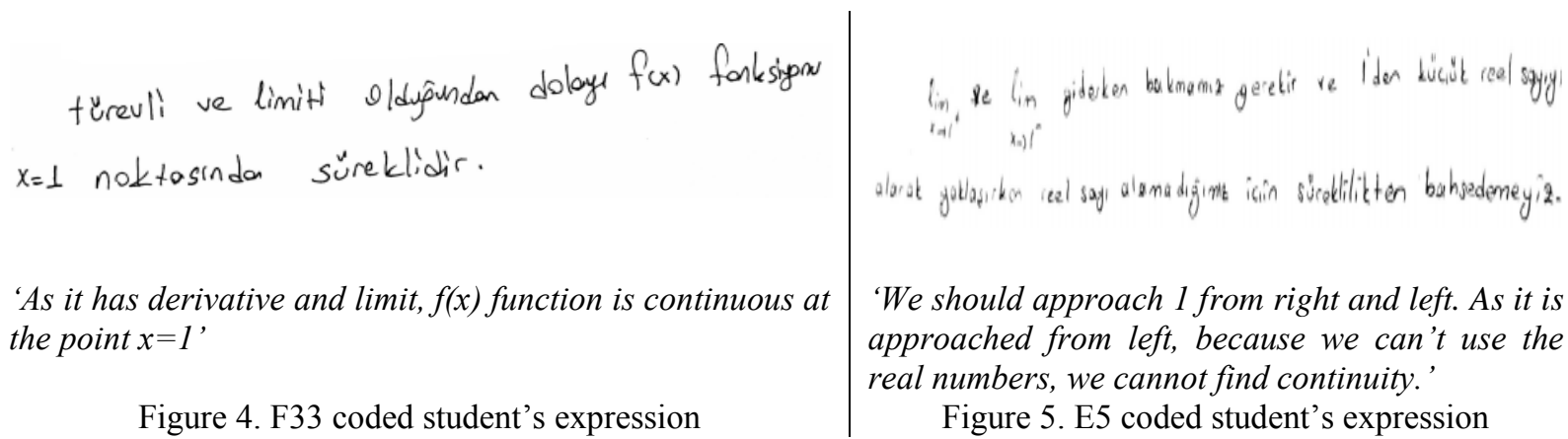

As it is indicated in Table1, the percentage of those who expressed the correct opinion related to that there was no solution of the problem of derivative stated in CPKFRCLCDI, according to the faculties are: for the Faculty of Education is $2 \%$ and for the Faculty of Science and Letters is $4 \%$. Totally, while $3 \%$ of all the participants expressed opinion as there was no solution for the problem related to the derivative, $34 \%$ expressed incorrect answers about the solution and $63 \%$ of them directly started to solve without expressing opinion. The expressions of F3 (correct opinion) and E29 (incorrect opinion) coded participants related to the existence of the solution are as follows;

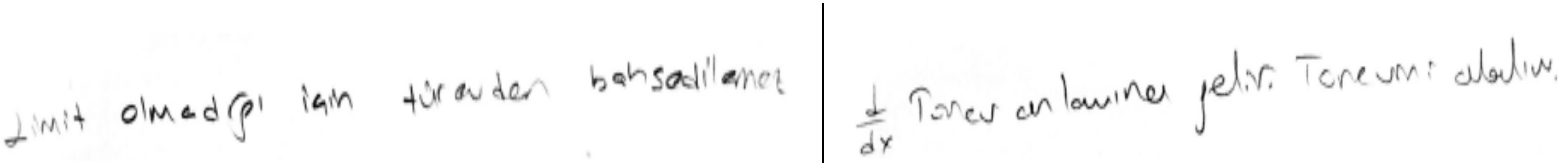

$$
\begin{aligned}
& \text { 'As there isn't limit, the derivative cannot be calculated.' } \frac{d}{d x} \text { 'means derivative, let's calculate its derivative.' } \\
& \text { Figure 6. F3 coded student's expression } \quad \text { Figure 7. E29 coded student's expression }
\end{aligned}
$$

As it is indicated in Table 1, the percentage of those who expressed the correct opinion related to that there was no solution of the problem of integral stated in CPKFRCLCDI, according to the faculties are: for the Faculty of Education is $4 \%$ and for the Faculty of Science and Letters is $0 \%$. Totally, while $2 \%$ of all the participants expressed opinion as there was no solution for the problem related to the integral, $20 \%$ expressed incorrect answers about the solution and $78 \%$ of them directly started to solve without expressing opinion. The expressions of F20 (incorrect opinion) and E3 (correct opinion) coded participants related to the existence of the solution are as follows;

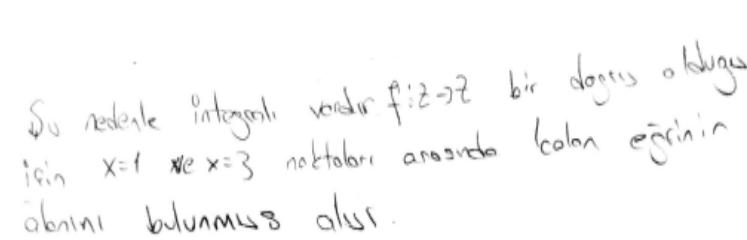

'Thus, it has integral. As $f: Z \rightarrow Z$ is a straight, the curve of the rest straight is calculated between $x=1$ and $x=3$,

Figure 8. F20 coded student's expression

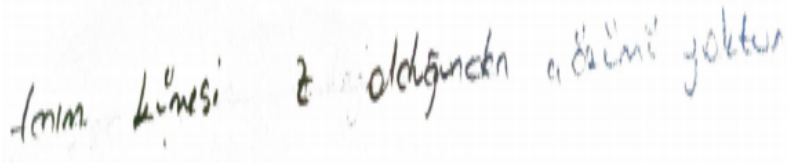

'As the description set is Z, it has no solution.'

Figure 9. E3 coded student's expression 
3.2 The Findings Related to the Second Sub-problem; What are the procedural learning levels of students in the department of secondary school mathematics teacher training and the department of mathematics in the faculty of science and letters related to limit, continuity, derivative and integral?

Within the scope of this sub-problem, the solutions of the participants who started to solve the problems without expressing opinion, 'Does the $\mathrm{f}$ function continuous at $\mathrm{x}=1$ point for the function as ' $f: Z \rightarrow Z$ and $f(x)=2 x+$ $1^{\prime} \lim _{x \rightarrow 1}(2 x+1)$ ', ' $\frac{d}{d x}(2 x+1)$ ' and ' $\int_{1}^{3}(2 x+1) d x$ ' were examined. The distributions of participants' solutions of the related concept, according to the categories as capability-incapability of solving the problems correctly were indicated in Figure 10.

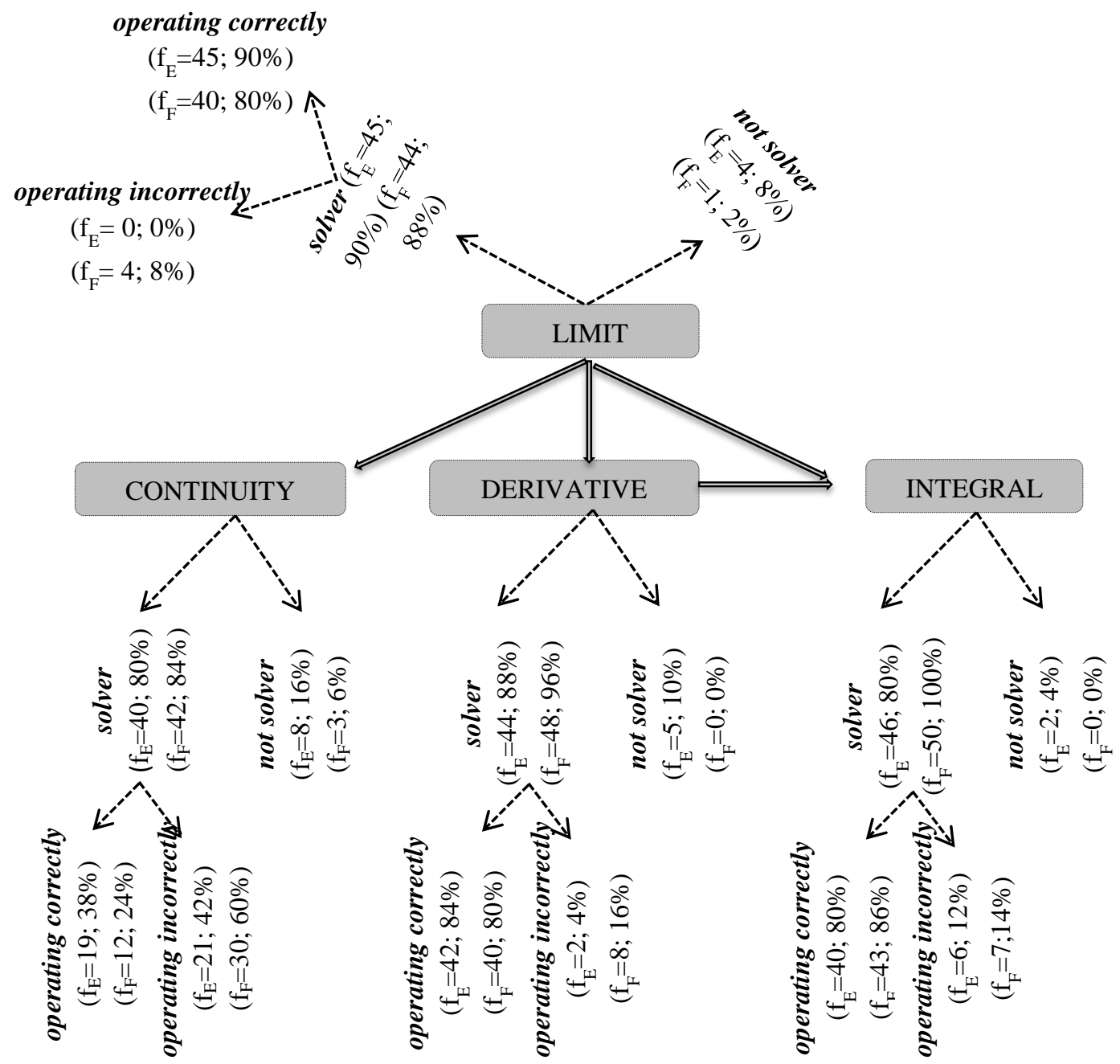

Figure 10. The distributions of the solutions to the procedural problems by the participants

As it is indicated in Figure 10, although, actually, there was no solution for the limit problem stated in CPKFRCLCDI, the percentage of those who could operate during the solving process according to the faculties are: for the Faculty of Education is $92 \%$ and for the Faculty of Science and Letters is $89 \%$. Totally, while $91 \%$ of those of the participants who could not express that there was no solution for the relevant problem, could finish the solving in terms of the operations, $4 \%$ made mistakes during the process, $5 \%$ of them did not make any operation. The solutions belong to F47 (operating incorrectly) and E49 (operating correctly) coded participants in terms of the operations are as follows; 


$$
\begin{aligned}
& \lim _{x+1}(2 x+1)=3 \text { limite youdor. } \\
& \lim _{x^{x} \rightarrow 1}(2 x+1)=-1 \\
& \text { sagader we solda youlosildọnda } \\
& 3 \neq-1 \text { old don limitr yeturi }
\end{aligned}
$$

Figure 11. F47 coded student's solution

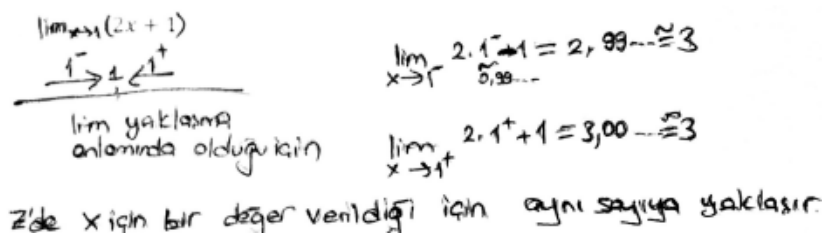

'As limit means approaching, as a value for $x$ is given to $Z$, then approach the same value.'

Figure 12. E24 coded student's solution

As it is indicated in Figure 10, although, actually, there was no solution for the continuity problem stated in CPKFRCLCDI, the percentage of those who could operate during the solving process according to the faculties are: for the Faculty of Education is $39 \%$ and for the Faculty of Science and Letters is $26 \%$. Totally, while $33 \%$ of those of the participants who could not express that there was no solution for the relevant problem, they could finish the solving in terms of the operations, $55 \%$ made mistakes during the process, $12 \%$ of them did not make any operation. The solutions belong to F39 (operating correctly) and E22 (operating incorrectly) coded participants in terms of the operations are as follows;

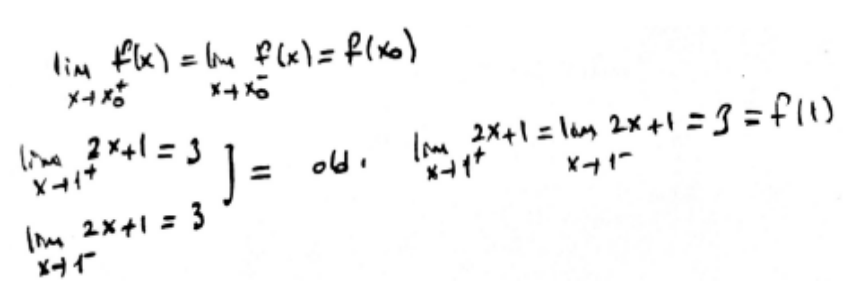

Figure 13. F39 coded student's solution

$$
\begin{aligned}
& \lim _{x \rightarrow 1^{+}} 2 x+1=3 \\
& \lim _{x \rightarrow 1^{-}} 2 x+1=3
\end{aligned} \quad 3=3 \text { süreklidir. }
$$

\section{' $3=3$ it is continuous'}

Figure 14. E22 coded student's solution

As it is indicated in Figure 10, although, actually, there was no solution for the derivative problem stated in CPKFRCLCDI, the percentage of those who could operate during the solving process according to the faculties are: for the Faculty of Education is $86 \%$ and for the Faculty of Science and Letters is $83 \%$. Totally, while $85 \%$ of those of the participants who could not express that there was no solution for the relevant problem, could finish the solving in terms of the operations, $10 \%$ made mistakes during the process, $5 \%$ of them did not make any operation. The solutions belong to F30 (operating incorrectly) and E29 (operating correctly) coded participants on account of the operation are as follows;

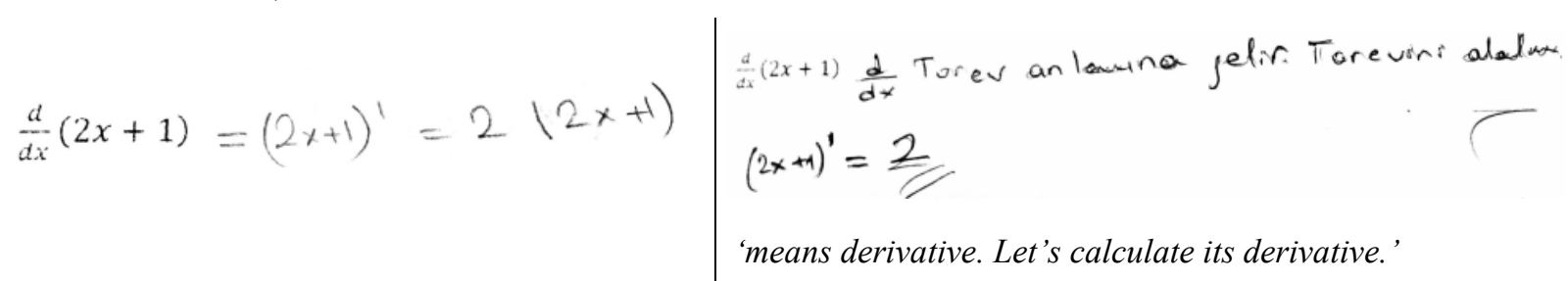

Figure 15. F30 coded student's solution

Figure 16. E29 coded student's solution

As it is indicated in Figure 10, although, actually, there was no solution for the integral problem stated in CPKFRCLCDI, the percentage of those who could operate during the solving process according to the faculties are: for the Faculty of Education is $83 \%$ and for the Faculty of Science and Letters $86 \%$. Totally, while $85 \%$ of those of the participants who could not express that there was no solution for the relevant problem, could finish the solving in terms of the operations, $13 \%$ made mistakes during the process, $2 \%$ of them did not make any operation. The solutions belong to F12 (operating correctly) and E20 (operating incorrectly) coded participants on account of the operation are as follows; 


$$
\int_{1}^{3}(2 x+1) d x=x^{2}+\left.x\right|_{1} ^{3}=12-2=10
$$

Figure 17. F12 coded student's solution

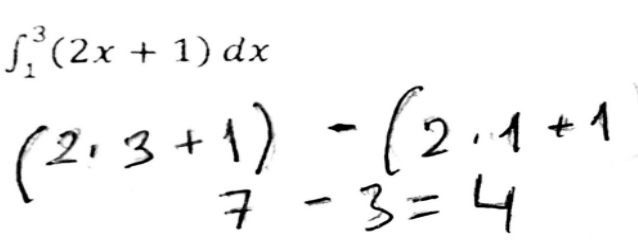

Figure 18. E20 coded student's solution

\section{Results, Discussion and Recommendations}

Within the scope of this study, it was aimed to investigate the hierarchical structure of mathematics emerged in university students' minds, the concepts of limit, continuity, derivative and integral from the perspective of students in the department of secondary school mathematics teacher training and the department of mathematics in the faculty of science and letters, the following results were reached.

It was determined that the participants could not constitute the hierarchical structure of the limit-continuity-derivative-integral concepts conceptually. It was noticed that the participants did not have enough conceptual knowledge of the existence of solving derivative and definite integral problems defined with the help of limit and limit concept. This result reports similarity with the results showing the students have learning difficulties in the concepts of limit, continuity, derivative, integral (Baki and Çekmez, 2012; Biber and Argün, 2015; Cornu, 1991; Davis and Vinner, 1986; Hashemi, Abu, Kashefi, Mokhtar and Rahimi, 2015; Kula and Bukova Güzel, 2015; Özkaya, Işık and Konyalığlu, 2014; Sağlam and Bülbül, 2012; Szydlik, 2000; Tall and Vinner, 1981; Tangül, Barak and Özdaş, 2015; Williams, 1991) or misconceptions (Akbulut and Işık, 2005; Baştürk and Dönmez, 2011; Bergthold, 1999; Bezuidenhout, 2001; Cornu, 1991; Davis and Vinner, 1986; Dönmez, 2009; Gray and Tall,1991; Jordaan, 2005; Orton, 1983; Szydlik, 2000; Tall and Vinner, 1981; Tall, 1993; Williams,1989, 1991). As the situation handled in this study for the solutions of relevant concepts originates from the accumulation point, which can be considered as basic, similarly, in the study by Çetin, et al. (2012), it was pointed out that the students did not understand this concept at all. As it is investigated within the scope of the faculties, it can be expressed that the participants from the faculty of education have more knowledge on this topic than the students from the faculty of science and letters.

As it is analysed in terms of procedural knowledge, it was noticed that the operational steps to be applied in solving the problems related to limit, derivative and definite integral were obtained by most of the students, but almost half of the students have not the procedural acquisitions of the continuity. This result, which is related to integral concept, shows similarity with the result by Oberg (2000) reporting the participants are able to use algorithms in solving a definite integral, which is given as algebraically.

As it is compared in terms of the procedures, it can be expressed that there is no difference between the participants from the faculty of education and the participants from the faculty of science and letters.

As these results gathered, briefly, it was determined that the participants were not able to learn the concepts of limit-continuity-derivative-integral conceptually. Although the students could not form the hierarchical structure among the concepts in their minds, it was noticed that they were able to learn the procedural knowledge related to each concepts independently. Within the lights of these results, it is realised that the hierarchical structure of mathematics within the scope of certain concepts was not formed in mind by most of the participants.

From these results, it is recommended to the teachers that, in solving problems related to these concepts, one of the examples should be placed, in a way, to make the students realize the identifiability of these concepts depending on the studied set. Furthermore, it is thought that the acquisition of this awareness even for other concepts can contribute to form the hierarchical structure of mathematics in students' minds accurately.

\section{References}

Akbulut, K., \& Iş1k, A. (2005). Investigation of effectiveness of interactive teaching strategy on understanding of limit concept and encountered misconceptions in this process. Kastamonu Education Journal, 13(2), 497-512.

Baki, M. and Çekmez, E. (2012). Prospective elementary mathematics teachers understandings about the formal definition of limit. Turkish Journal of Computer and Mathematics Education, 3(2), 81-98. 
Balc1, M. (1997). Matematik analiz cilt II (Calculus II). Ankara: Balc1 Yayınları.

Baştürk, S., \& Dönmez, G. (2011). Mathematics student teachers' misconceptions on the limit and continuity concepts. Necatibey Faculty of Education Electronic Journal of Science and Mathematics Education, 5(1), 225-249.

Bekdemir, M., \& Işık, A. (2007). Evaluation of conceptual knowledge and procedural knowledge on algebra area of elementary school students. The Eurasian Journal of Educational Research, 28, 9-18.

Bergthold, T.A. (1999). Patterns of analytical thinking and knowledge use in students' early understanding of the limit concept. Unpublished Doctoral Dissertation, University of Oklahama, Oklahama.

Bezuidenhout, J. (2001). Limits and continuty: some conceptions of first-year students. International Journal of Mathematics Education in Science and Techonolgy, 32(4), 487-500. http://dx.doi.org/10.1080/00207390010022590

Biber, A. Ç. and Argün, Z. (2015). The relations between concept knowledge related to the limits concepts in one and two variables functions of mathematics teachers candidates. Bartin University Journal of Faculty of Education, 4(2), 501-515. http://dx.doi.org/10.14686/buefad.26967

Bogdan, R. C., \& Biklen, S. K. (2007). Qualitative research for education: an introduction to theory and methods (5th ed.). USA: Pearson Education, Inc.

Cornu, B. (1991). Limits. In D. Tall (Ed), Advanced mathematical thinking (153-166). Dordrect, The Netherlands: Kluwer Academic.

Çetin, F.Ö., Dane, A., \& Bekdemir, M. (2012). A concept of "accumulation point" and its usage. Necatibey Faculty of Education Electronic Journal of Science and Mathematics Education, 6(2), 217-233.

Davis, R. B., \& Vinner, S. (1986). The notion of limit; some seemingly an avoidable misconception stages, J. Math. Behav., 5, 281-303.

Dönmez, G. (2009). Assessment of pre-service mathematics teachers? pedagogical content knowledge about limit and continuity. Unpublished Master Dissertation, Marmara Univesrity.

Gray, E. M., \& Tall, D. O., (1991). Duality, Ambiguity and flexibility in successful mathematical thinking, Proceedings of PME XIII, Assisi, 2, 72-79.

Hashemi, N., Abu, M. S., Kashefi, H., Mokhtar, M., \& Rahimi, K. (2015). Designing learning strategy to improve undergraduate students' problem solving in derivatives and integrals: a conceptual framework. EURASIA Journal Of Mathematics, Science \& Technology Education, 11(2), 227-238. http://dx.doi.org/10.12973/eurasia.2015.1318a

Hiebert, J., \& Lefevre, P. (1986). Conceptual and procedural knowledge in mathematics: An introductory analysis (pp. 1-27). Hillsdale, NJ: Lawrence Erlbaum Associates, Inc.

Jordaan, T. (2005). Misconceptions of the limit concept in a mathematics course for engineering students. Unpublished Master of Science Dissertation, University of South Africa.

Kandemir, M. (2004). The permanent concepts in mathematics. Kastamonu Education Journal,12(2), $397-416$.

Kula, S. \& Bukova Güzel, E. (2015). Reflections of Mathematics Student Teachers' Knowledge Related to the Purposes of the Curriculum on Their Limit Teaching. Journal of Theoretical Educational Science, 8(1), 28-49. http://dx.doi.org/10.5578/keg.8758

McMillan, J. H. (2000). Educational research fundamentals for the consumer. USA: Longman.

Nesbit, T. (1996). What counts? Mathematics education for adults. Adult Basic Education, 6(2), 69-83.

Oberg, T.D. (2000). An investigation of undergraduate calculus students conceptual understanding of the definite integral. Unpublished PhD Dissertation, University of Montana.

Orton, A. (1983). Students' understanding of differentiation. Educational Studies in Mathematics, 14(3), $235-250$. http://dx.doi.org/10.1007/BF00410540

Özdemir, H. B. (2000). Matematik öğretimde tanım, terim ve sembollerin önemi, H.Ü. Fen Bilimleri Eğitimi Kongresi Sempozyumu, 19-20 September, İzmir, 647-649. 
Özkaya, M., Işık, A., \& Konyalığlu, A. (2014). Proofing and counter-exampling performances of students in the elementary mathematics education department for continuous functions. Middle Eastern \& African Journal of Educational Research, 11, 26-42.

Patton, M. Q. (2002). Qualitative research \& evaluation methods (3th ed.). USA: SAGE Publications, Inc.

Rittle-Johnson, B. \& Schneider, M. (2012). Developing conceptual and procedural knowledge of mathematics. In R. Kadosh \& A. Dowker (Eds), Oxford Handbook of Numerical Cognition. Oxford Press.

Sağlam, Y., \& Bülbül, A. (2012). University students visual and analytic strategies. H. U. Journal of Education, 43, 398-409.

Szydlik, J.E. (2000). Mathematical Beliefs and conceptual understanding of the limit of a function. Journal for Research in Mathematics Education, 31(3), 258-276. http://dx.doi.org/10.2307/749807

Tall, D. (1993). Students difficulties in calculus. Proceeding of Working Group 3 on Students' Difficulties in Calculus. ICME-7, Québec, Canada, (1993), 13-28.

Tall, D., \& Vinner, S. (1981). Concept image and concept definition in mathematics with particular reference to limits and continuity. Educational Studies in Mathematics, 12, 151-169. http://dx.doi.org/10.1007/BF00305619

Tangül, K., Barak, B., \& Özdaş, A. (2015). Students' concept definitions and concept images about limit Concept. Anadolu Journal Of Educational Sciences International, 5(1), 88-114.

Williams, R.S. (1989). Understanding of the limit concept in college calculus students. Unpublished Doctoral Dissertation. University of Winconsin-Madison.

Williams, S. (1991). Models of limit held by college calculus students. Journal for Research in Mathematics Education, 22(3), 219-236. http://dx.doi.org/10.2307/749075

Yıldırım, A. \& Şimşek, H. (2006) Sosyal bilimlerde nitel araştırma yöntemleri (Qualitative Research Methods in Social Sciences) (6th ed.). Ankara: Seçkin Yayınevi. 